GEOUSP - Espaço e Tempo, São Paulo, № 23, pp. 193 - 205, 2008

\title{
TESES DE DOUTORADO E DISSERTAÇÕES DE MESTRADO DEFENDI DAS
}

\author{
(Novembro de 2007 a Maio de 2008)
}

\section{Teses de Doutorado}

\section{Mapas para o turismo e a interatividade: proposta teórica e prática}

\section{Sérgio Ricardo Fiori}

Orientadora: Profa. Dra. Regina Araújo Almeida

Os mapas inserem-se no dia-a-dia das pessoas de forma cada vez mais presente. A mídia - telejornais, revistas, anúncios de propaganda imobiliária, internet, jornais, mapas artísticos e de propaganda, etc. - ao utilizá-los como um meio de comunicação, na maioria das vezes, ignora algumas regras básicas na relação produtor e público usuário. No bojo desses materiais cartográficos, encontram-se os mapas turísticos, que usualmente são confeccionados por artistas e ilustradores e não por geógrafos ou cartógrafos. Esta pesquisa, fundamentada essencialmente na cartografia temática, propõe aprofundar e estreitar a metodologia iniciada e experimentada no mestrado, que abordou o uso das representações pictóricas e da visão oblíqua em mapas direcionados a turistas e leigos em cartografia. Tal recurso gráfico possibilita um menor nível de abstração da representação gráfica, trazendo comprovadamente uma maior facilidade de leitura da informação cartográfica. Além disso, é visualmente mais atrativa, por evocar conotações visuais, afetivas e emotivas. Ainda utilizando a pictografia e os símbolos de informação pública, é proposta uma legenda específica aos mapas turísticos, símbolos esses que são elaborados para que as pessoas os vejam e os interpretem/ compreendam sem nunca tê-los visto antes. Entretanto, é bom frisar que os símbolos e mapas convencionais também farão parte do produto cartográfico final, até porque, mesmo trabalhando potencialmente com mapas pictóricos para o setor do turismo, algumas informações são particularmente mais apropriadas e diretas se feitas por meio da convencionalidade. Soma-se a esta discussão, o desenvolvimento de mapas temáticos para o turismo em meio digital. Esses novos recursos técnicos possibilitam o desenvolvimento de mapas não-limitados a uma folha de papel, proporcionando representações interativas, animadas, sonorizadas, em diferentes idiomas, entre outras possibilidades. Nesse item, além da elaboração e uso do produto em si, há uma preocupação particular em encontrar relações entre o mapa, a mencionada interatividade e o usuário, nunca esquecendo que o material temático dirigido ao turismo deve não só se preocupar em fazer com que a informação seja adequadamente apreendida pela leitura como também se esmerar em ser atrativo, sedutor, a fim de estimular a curiosidade sobre a localidade representada. 


\section{A disputa pela hegemonia do espaço na baía dos Castelhanos}

Paulo da Silva Noffs

Orientador: Prof. Dr. Heinz Dieter Heidemann

Este trabalho trata do processo de transformação do espaço rural da produção mercantil simples de alimentos em espaço urbano relacionado ao turismo na Baía dos Castelhanos, Ilhabela. A produção mercantil simples até meados da década de 1960 articulavase com o mercado de Santos por intermédio dos barcos a motor. A implantação da infra-estrutura rodoviária no Litoral Norte, simultaneamente pôs fim a este tipo de comércio e favoreceu o desenvolvimento do turismo na região. Atualmente, o turismo local responde a lógica da reprodução capitalista e está subordinado principalmente ao crescimento da metrópole de São Paulo. A disputa pela hegemonia do espaço na Baía dos Castelhanos está associada, por sua vez, à relação que se estabelece entre a população caiçara remanescente, os diversos segmentos de turismo e turistas e o Estado que regulamenta o uso do território. A relação é conflituosa em decorrência da forma como esses atores desejam se apropriar da renda gerada pela valorização do espaço.

\section{Organização espacial dos componentes da paisagem da baixa Nhecolândia - Pantanal de Mato Grosso do Sul}

Erminio Fernandes Orientador: Prof. Dr. José Pereira de Queiroz
Neto

Esta tese de doutoramento tem o objetivo de identificar os padrões de organização espacial dos principais componentes da paisagem na Baixa Nhecolândia e analisar suas relações com as estruturas regionais e as dinâmicas hídricas. Para tanto, foram utilizados produtos de sensoriamento remoto e técnicas do geoprocessamento de imagens de satélites com bancos de dados georreferenciados dos elementos da área de estudo, além de procedimentos de controle de campo das informações levantadas. A Baixa Nhecolândia sofre influência da dinâmica das estruturas lineares aparentes nas serranias de seu entorno e, a partir de um estudo mais acurado, pode-se evidenciar no sutil relevo do Pantanal registros morfoestruturais correlacionados a esses lineamentos. Por outro lado, feições do relevo associadas a hidrodinâmica do Leque Aluvial do Rio Taquari distribuem-se na região, apresentando padrões de organização diferenciados das formas ligadas às morfoestruturas. Desta forma, os elementos da paisagem da Baixa Nhecolândia apresentam distribuição, padrão de organização espacial e formas resultantes, dentre outros, de 2 processos dinâmicos que são objetos desta tese: 1) processos estruturais regionais, 2) processos hidrodinâmicos do leque aluvial do rio Taquari.

\section{Relevo, processos geoecológicos e sócio/ reprodutores e a fragilidade ambiental da bacia do ribeirão Piracicamirim/ SP}

\section{Sueli Mançanares Leme}

Orientador: Prof. Dr. Adilson Avansi de Abreu

O estudo teve por objetivo mostrar que as formas de relevo observadas na Bacia do Piracicamirim/SP traduzem a dependência genética de todo o conjunto de estruturas que se articulam no geossistema paisagístico dessa unidade geográfica, tendo por isso, grande importância como indicadoras da dinâmica precedente e da situação atual do mesmo, razão pela qual, o seu estudo foi tomado como fundamental não só para explicar a evolução dos processos geoecológicos da área mas, também, como norteador e, portanto, subsídio para o (re) planejamento futuro da referida bacia. A escolha da bacia em questão se justifica por sua meso-escala, o que a coloca, 
Teses de Doutorado e Dissertações de Mestrado Defendidas

(Novembro de 2007 a Maio de 2007), pp. 193 - 205

metodologicamente como adequada, para estudos de tendências, padrões de comportamento e de processos. A elaboração da carta morfodinâmica como método da pesquisa decorreu da intenção de avaliar a participação relativa do relevo na dinâmica dos processos, bem como da meta de identificar os graus de fragilidade ambiental. O estudo comprovou que a dinâmica das formas de relevo e as propriedades adquiridas em sua gênese determinaram a evolução dos processos geoecológicos e sócio-reprodutores observados na área; reforçou a adequação da perspectiva sistêmica e da sua materialização em uma carta síntese para estudos geomorfológicos com a pretensão técnica de subsidiar planejamento territorial; comprovou os riscos decorrentes da adoção, para o estudo de realidades complexas, de procedimentos exclusivamente analíticos; disponibilizou elementos de crítica em relação a procedimentos empíricos e computacionais de cartografação geomorfológica; identificou a relação relevo/solo/uso da terra como a que principalmente está a responder pela fragilidade ambiental na bacia; disponibilizou o ferramental que poderá subsidiar as necessárias ações públicas de (re) planejamento urbano/rural e de educação ambiental da área.

\section{Metodologia para elaboração de modelos de fragilidade ambiental utilizando redes neurais}

\section{Christiane Sporl}

Orientador: Prof. Dr. Ailton Luchiari

Este trabalho aborda o desafio da modelagem da fragilidade ambiental, que implica em, além de compreender a intrínseca e dinâmica relação existente entre as componentes físicas, bióticas e sócioeconômicas dos sistemas ambientais, em traduzir esse conhecimento num modelo matemático. Para elucidar essa dificuldade foram apresentados e comparados os resultados gerados por dois modelos empíricos de fragilidade ambiental amplamente utilizados no planejamento físico-territorial brasileiro (CREPANI et al. 2001 e ROSS, 1994). Estes dois modelos foram aplicados em duas áreasteste, com resultados bastante divergentes. Neste contexto de incertezas, este trabalho testou a viabilidade e a confiabilidade de uma nova ferramenta a ser aplicada na elaboração de modelos de fragilidade ambiental, as redes neurais artificiais (RNAs). Empregando os conhecimentos e experiências de especialistas na área em questão, extraídos das respostas dadas por estes durante a comparação de variáveis e cenários aplicados através dos programas adaptados para esta finalidade: Pesquisa de Calibração, Pesquisa de Escalonamento de Variáveis e Pesquisa de Avaliação de Cenários. Estes programas geraram uma base de dados referente ao modo de avaliação de cada especialista quanto à fragilidade ambiental, sendo aplicada no treinamento das RNAs, para que a rede assimilasse o padrão de avaliação deste especialista. Os resultados comprovam de que é possível emular, com razoável confiabilidade, o padrão de avaliação de especialistas na definição da fragilidade dos sistemas ambientais, eliminando assim, a arbitrariedade e a subjetividade do processo de elaboração de modelos de fragilidade ambiental. Este trabalho não propõe um novo modelo, mas uma metodologia para a construção de modelos, utilizando redes neurais artificiais, dando um primeiro passo em busca de novas técnicas, temidas pelos geógrafos, mas necessárias para a evolução da ciência geográfica. 


\section{O pão nosso de cada dia nos dai hoje... J osué de Castro e a inclusão da fome nos estudos geográficos no Brasil}

Antonio Alfredo Teles de Carvalho

Orientadora: Profa. Dra. Iraci Gomes de Vasconcelos Palheta

Contemplando um recorte temporal de dezessete anos (1937/1954), o trabalho apresentado inserese na área de história do pensamento geográfico. Está centrado na tese que o médico e geógrafo pernambucano J osué de Castro foi introdutor da 'geografia da fome' na história do pensamento geográfico no Brasil no interstício assinalado. Utilizando e concebendo o método geográfico como o único que permitia analisar a fome em toda a sua complexidade, sem dissociá-la das texturas do processo social subjacente a sua criação, o autor elucidou e denunciou esse espectro que assolava aproximadamente dois terços da humanidade do seu tempo. Nesse contexto, a sua obra seminal Geografia da Fome, publicada e 1946, constituiu-se num marco; primeiro, por introduzir um tema inédito dentro da Geografia no país, significativamente influenciada pela Escola Francesa e estudando os gêneros de vida, naturalmente voltava-se a análise da alimentação, sem entrementes fazer referência a fome; segundo, por provar que a fome consistia numa expressão biológica dos malefícios sociais especialmente nas periferias do capitalismo; e terceiro, em face a essa leitura, pelas possibilidades acenadas à análise do social na Geografia. Destarte, assume relevância e apresenta-se como uma expressiva referência da Geografia no Brasil e um imperativo no estudo da fome como tema passível de investigação pela mesma.

\section{O processo de transformação do território no noroeste do Paraná e a construção das novas territorialidades camponesas}

\section{Adélia Aparecida de Souza Haracenko}

Orientadora: Profa. Dra. Iraci Gomes de Vasconcelos Palheta
O objetivo do nosso esforço analítico neste trabalho de pesquisa incide na compreensão do processo de transformação de uma fração do território, iniciando pela análise do território original indígena até chegar ao desvendamento das novas territorialidades camponesas resultantes as da atuação do Movimento dos Trabalhadores Rurais Sem Terra - MST. É esta questão que norteia a presente pesquisa, cujo recorte geográfico é o Noroeste do Paraná, uma fração desse Estado que teve um rápido processo de transformação territorial num curto espaço de tempo. Para compreendermos esta metamorfose partimos do pressuposto de que a lógica da construção do território é uma unidade dialética em que simultaneamente ocorrem a construção, a destruição, a manutenção e, evidentemente, a transformação. Nesse contexto, procuramos desvendar tal processo através da identificação de três momentos históricos: o do território original indígena, o do advento da formação da propriedade privada, com o desenvolvimento da colonização, e por fim, o da construção das novas territorialidades camponesas, objeto da tese. Sendo assim, a análise das evidências para compreendermos o processo de transformação do território está desenvolvida da maneira a seguir descrita. Após a introdução, no primeiro capítulo, expomos os caminhos de construção da investigação, identificando o recorte geográfico em que ela ocorre e apresentando a reflexão teóricometodológica e os conceitos que sustentam esta pesquisa. No segundo capítulo, somando-nos às pesquisas dos estudiosos que tratam da questão indígena no Norte do Paraná, procuramos, da mesma maneira contribuir para a desmistificação do discurso hegemônico do "vazio demográfico" implantado nesta região no período em que estava sendo colonizada e mostrar que a região estudada, até um passado recente que coincide com o período da colonização, tinha como seus primeiros habitantes a população autóctone, sendo, portanto, território original dos povos indígenas. No terceiro capítulo, procuramos compreender, utilizando entrevistas com fontes orais, o desenvolvimento do processo de colonização 
Teses de Doutorado e Dissertações de Mestrado Defendidas

(Novembro de 2007 a Maio de 2007), pp. 193 - 205

que se inicia nos primórdios da década de 1950. Paralelamente à colonização, destacamos, igualmente os acontecimentos que envolvem os conflitos pela posse da terra na região. Por fim, no quarto capítulo o trabalho demonstra que após a fase de ocupação efetuada através da colonização, a partir de meados da década de 1980, ocorre uma nova forma de ocupação do território, desenvolvida pelo MST, a qual vai influenciar diretamente a construção das novas territorialidades camponesas, através das desapropriações dos grandes latifúndios improdutivos e imissão de posse aos camponeses.

\section{Geografia e ensino no Brasil e em Cuba: um estudo histórico-geográfico comparado}

\section{César Alvarez Campos de Oliveira}

Orientador: Prof. Dr. J osé William Vesentini

O objeto de estudo desta tese é o desenvolvimento da Geografia como matéria escolar no Brasil e em Cuba, desde seu surgimento até os dias atuais. O objetivo principal é a ampliação do debate e da reflexão sobre as funções e sobre a utilidade da Geografia escolar atual, assim como sobre nossas práticas como professores da disciplina. Para atingir tal objetivo, analisamos, dentro de um enfoque comparativo, os percursos da Geografia nos dois países em questão, dando prioridade aos aspectos relacionados à história do pensamento geográfico, assim como à sua institucionalização, aos fatores que a influenciaram, às transformações sofridas ao longo do tempo, aos seus objetivos principais e à sua configuração nos diferentes períodos históricos abarcados pelo estudo. Nesse sentido, abordamos de forma particularizada os principais elementos que identificamos como responsáveis pela constituição da estrutura conceitual da disciplina, atrelando-os aos contextos espaciais e históricos específicos e aos processos singulares de formação territorial de cada país. Para tanto, desenvolvemos estudos relacionados aos fatores internos e externos à disciplina, articulando-os aos processos de construção e afirmação da Geografia escolar. A abordagem comparativa permite a ampliação da visão sobre temas pertinentes à Geografia como ciência e como disciplina escolar, especialmente aqueles relacionados aos seus objetivos, à seleção e organização dos conteúdos, à metodologia e à formação docente. Nessa perspectiva, apresentamos, também, os principais aspectos relacionados à organização dos sistemas de ensino nacionais dos dois países, assim como a inserção da Geografia nessa estrutura maior. A partir dessa base, nos debruçamos sobre a análise de temas que consideramos fundamentais para repensarmos o futuro da Geografia escolar, como a construção da identidade nacional e a doutrinação patriótica, os livros didáticos, os programas oficiais da disciplina e a formação de professores. Como resultado final, considerando-se que os sistemas de ensino, a escola e o próprio currículo são construções sociais e, por isso, sujeitos a constantes transformações, esperamos ter contribuído para um tipo de reflexão que possa ser útil para repensarmos os rumos da Geografia escolar de cada um dos países.

\section{O patrimônio ambiental urbano de Corumbá- MS: identidade e planejamento}

\section{J oelson Gonçalves Pereira}

Orientador: Prof. Dr. Eduardo Abdo Yazigi

A presente pesquisa constitui uma abordagem sobre Corumbá, cidade edificada sob um platô calcário à margem direita do rio Paraguai, região noroeste do estado de Mato Grosso do Sul. O local é marcado por uma forte personalidade espacial, referenciada na sua fisiografia natural e na permanência de uma cultura material representativa enquanto bem patrimonial, em parte reconhecida como patrimônio histórico, paisagístico e artístico nacional. Estas características espaciais de Corumbá colocaramse como objeto desta investigação acadêmica, realizada sob a perspectiva conceitual de 
198 - GEOUSP - Espaço e Tempo, São Paulo, № 23, 2008

patrimônio ambiental urbano, privilegiando a reflexão sobre dois temas importantes e sempre atuais dentro do campo atuação da ciência geográfica: o planejamento e a identidade espacial dos lugares. Como resultado, a cidade revelou-se, diante de sua representatividade material, favorável em retratar a problemática que envolve a questão da preservação patrimonial no Brasil, bem como seus resultados afetos aos fatores de qualidade ambiental, de civilização urbana e identidade. Por fim, ressaltase que a leitura apresentada neste trabalho resulta de uma construção sistemática, referenciada nos propósitos estabelecidos pelo projeto de pesquisa iniciado no ano de 2003. As reflexões alcançadas no trato dessa temática resultaram de duas preocupações centrais referentes à realidade da área estudada e que constituíram os principais esforços de sua investigação: a caracterização dos elementos de cultura material e de fisiografia representativos do patrimônio ambiental urbano de Corumbá e a problemática que envolve sua preservação enquanto materialidade expressiva na definição de uma identidade espacial.

\section{Dissertações de Mestrado}

\section{Estado e terceiro setor na organização do espaço para o turismo no Vale do Ribeira}

\section{Carolina Todesco}

Orientadora: Profa. Dra. Rita de Cássia Ariza da Cruz

A presente pesquisa tem como estudo de caso a região do Vale do Ribeira, localizado no sul do Estado de São Paulo. A região possui uma população de cerca de 400 mil habitantes e apresenta os menores índices de desenvolvimento humano do estado mais rico do país, constituindo-se numa "área opaca" dentro da Região Concentrada. Por conter cerca de $20 \%$ dos remanescentes florestais da Mata Atlântica do Brasil, o Vale tem maior parte de seu território inserido em Unidades de Conservação implantadas, principalmente, a partir da década de 80 , restringindo suas atividades econômicas tradicionais (agricultura e extrativismo mineral e vegetal). Este fato sustenta o discurso, pronunciado pelos órgãos públicos e organizações do Terceiro Setor, de que o (eco)turismo é uma alternativa para o Vale, entendendo-o como uma atividade capaz de dinamizar a economia regional e, conseqüentemente, amenizar os problemas e conflitos sócio-ambientais. Esta pesquisa teve por objetivo analisar as ações e o papel do Estado na (re)organização do espaço para o desenvolvimento do turismo na região do Vale do Ribeira, considerando também, o papel do chamado Terceiro Setor neste processo. Para isso, realizamos um levantamento das políticas públicas de desenvolvimento regional e de turismo, como também dos projetos desenvolvidos pelas organizações do Terceiro Setor direcionados ao Vale. Desta forma, pudemos observar que com as mudanças dos paradigmas orientadores das políticas públicas na década de 80 , juntamente com a redemocratização, avanço do neoliberalismo e enxugamento da máquina estatal, o Estado até então centralizador da formulação, decisão e execução das políticas públicas, passa a deliberar às organizações do Terceiro Setor a incumbência de planejar o desenvolvimento regional do Vale do Ribeira, atuando por meio do financiamento de pequenos projetos. Esta nova face do Estado faz com que o desenvolvimento do turismo no Vale, em certa medida, dependa do nível de organização social de cada município ou comunidade e da capacidade destes de formular projetos para a captação de recursos públicos, ou do interesse de organizações exógenas em implantar projetos na região. 
Teses de Doutorado e Dissertações de Mestrado Defendidas

(Novembro de 2007 a Maio de 2007), pp. 193 - 205

\section{O sistema ferroviário paulista: um estudo sobre a evolução do transporte de passageiros sobre trilhos}

Célia Regina Baider Stefani

\section{Orientador: Prof. Dr. Francisco Capuano} Scarlato

Nos últimos anos do século $X X$, o Sistema Ferroviário Paulista estampou, constantemente, manchetes da mídia impressa e televisiva. O mote das reportagens era quase sempre o mesmo: estações abandonadas e depredadas, má utilização do material permanente, carros de passageiros, locomotivas e vagões apodrecendo nos pátios, desconsideração ao usuário com a erradicação dos trens de longo percurso. O que as reportagens quase nunca apresentavam, no entanto, é a gênese desse quadro de degradação, que teve suas bases fincadas, entre outros fatores, na escolha política pelo transporte rodoviário e na privatização da malha ferroviária. Objetivando trazer à tona tal realidade, a presente dissertação procurou analisar a espacialidade e a história da evolução do Sistema Ferroviário no Estado de São Paulo, enfocando, especialmente, o transporte de passageiros, seja em longopercurso, seja na Região Metropolitana da capital. Para tanto, analisouse, inicialmente, a implantação e o desenvolvimento do Sistema Ferroviário em São Paulo, relacionando-o à produção cafeeira e ao processo de urbanizaçãoindustrialização da capital paulista. Num segundo momento, discutiu-se as políticas de implementação do Sistema Rodoviário e suas conseqüências para o transporte ferroviário no Estado, discorrendose também sobre as alterações administrativas das ferrovias. Por fim, pôde-se criticar a privatização da Rede Ferroviária Federal e as recentes transformações no transporte metroferroviário da capital. Acredita-se, desta forma, que o trabalho apresenta reflexões - apoiadas numa revisão da literatura a respeito do tema, e em dados e apontamentos de reportagens de revistas especializadas e da grande mídia - que possam servir para a construção de conjecturas acerca do futuro do transporte sobre trilhos no Estado de São Paulo.

\section{Região sisaleira da Bahia: a reorganização do espaço geográfico da Sisalândia a partir da criação da APAEB}

Écio Aparecido Ricci

Orientadora: Profa. Dra. Rita de Cássia Ariza da Cruz

A presente dissertação procurou analisar a reorganização espacial e o desenvolvimento da Sisalândia, inserida na Região Sisaleira da Bahia, impulsionados pelas ações desenvolvidas através da Associação de Desenvolvimento Sustentável e Solidário da Região Sisaleira - APAEB, uma organização socioeconômica articulada pela sociedade civil, gerenciada pelo movimento social da região sisaleira e apoiada por organizações não governamentais, nacionais e estrangeiras. Efetua-se uma caracterização da Sisalândia, trabalhando os elementos tradicionais e os novos elementos de sua estrutura, destacando o processo produtivo do sisal e as ações do Estado e da APAEB. Analisa-se, também, as ações das Comunidades Eclesiais de Base e dos sindicatos de trabalhadores rurais, que a partir da década de 1970, foram decisivas para promover a formação de organizações sociais que possibilitaram o processo de reorganização espacial na escala regional. Assim, através de uma análise interdisciplinar da realidade concreta são reconstruídos os processos históricos que levaram à formação das associações de pequenos produtores rurais, desvendando as estruturas sociais, o desenvolvimento recente e a reorganização do espaço geográfico da região sisaleira da Bahia, em particular dos municípios que compõem a Sisalândia. 


\section{Urbanização e turismo em Bertioga - o caso da praia de I ndaiá}

André Luiz Sabino

Orientadora: Profa. Dra. Rita de Cássia Ariza da Cruz

O desafio ao longo dessa investigação foi o de encontrar nexos espaciais da atividade do turismo a partir de um estudo de caso. Partimos da noção do espaço como um conjunto indissociável de objetos e de ações, buscamos apreender a produção do espaço em Bertioga e no loteamento Jardim Indaiá. Os objetos incorporados a este espaço, ao longo do tempo - funcionais ou refuncionalizados, nos permitiram cindir a totalidade, encontrando quais foram as principais variáveis que explicam a atual configuração espacial e, para isso, a noção de evento foi fundamental. O turismo é por nós considerado como uma prática social e uma atividade produtiva, que pressupõe o consumo do espaço, que usa os sistemas de objetos existentes, bem como, não raras vezes, cria um novo, ancorado em um sistema de ações, existente ou a ser criado, no imbricado jogo de relações entre mercado, Estado e sociedade. O estudo de Indaiá, um loteamento da praia da Enseada, no município de Bertioga, nos foi fundamental por permitir a análise do papel dos sujeitos sociais, os mais e os menos hegemônicos bem como os hegemonizados, incluindo nesta equação o espaço, o turismo, o capital imobiliário, o poder público e a sociedade.

Santo André: (re) ordenação sócio espacial e implicações do período técnico-científicoinformacional a partir dos anos 90

\section{Rodrigo Altair Pinho}

Orientadora: Profa. Dra. Maria Mônica Arroyo

O trabalho visa abordar as transformações espaciais ocorridas na cidade de Santo André situada na região metropolitana de São Paulo, ao longo dos últimos vinte anos tendo como base a caracterização dos meios geográficos proposta por Milton Santos. Para isto, nos remeteremos em alguns momentos a tempos pretéritos vividos na cidade, sobretudo por volta da década de 1960, em que presenciamos o advento de um meio técnicocientífico, materializado através da consolidação de indústrias do ramo metalúrgico, automobilístico e de auto-peças. Não pretendemos tecer uma abordagem do município andreense em dois períodos, porém, fez-se necessário, em alguns momentos da pesquisa, considerar as formas espaciais e atividades econômicas gestadas nas décadas de 60 e 70, para chegarmos à emergência do meio técnio-científicoinformacional, na segunda metade da década de 1980, foco da análise desta dissertação. No período atual, constatamos, a partir da pesquisa realizada, as seguintes transformações: a) remodelação dos processos produtivos de muitas empresas, através da utilização de novas técnicas e do uso intensivo de capitais; b) desconcentração industrial relativa no município perante à novas áreas que se industrializaram no território brasileiro a partir do final do século $X X$, em função da emergência de novas possibilidades técnicas que propiciaram uma expansão para além dos tradicionais pólos industriais, como a região do ABC paulista, constituindo assim, neste período, uma nova divisão territorial do trabalho no Brasil; c) substituição na ocupação de áreas ligadas a ramos de atividade industrial pelo setor de serviços, que refletiram mudanças significativas na vida social e na constituição urbana e econômica da cidade; d) intervenções urbanísticas através de ações consorciadas entre agentes públicos e privados, visando assegurar novas formas de inserção do espaço público municipal por meio do planejamento urbano; e) ação política do poder público municipal através da intervenção dos agentes municipais na melhoria das infra-estruturas urbanas, almejando a viabilização de demandas por rápida circulação e fluidez, características do meio técnico científicoinformacional. Em face destas transformações, constatamos que o espaço local foi reconstituído para atender a 
Teses de Doutorado e Dissertações de Mestrado Defendidas

(Novembro de 2007 a Maio de 2007), pp. 193 - 205

estes imperativos que sobretudo as grandes empresas, passaram a requerer no contexto da globalização.

\section{A produção do lugar na periferia da metrópole paulistana}

Fabiana Valdoski Ribeiro

Orientadora: Profa. Dra. Ana Fani Alessandri Carlos

A problemática urbana sobre a qual nos debruçamos na presente pesquisa referese aos processos de degradação da vida dos habitantes da metrópole, não apenas material, mas, sobretudo, resultante do empobrecimento das possibilidades de apropriação dos lugares da cidade. Tal apropriação se reduz, dialeticamente, pelas estratégias de dominação do espaço, que impõem normas ao uso do espaço pelos habitantes como condição necessária a um espaço produto, condição e meio da acumulação capitalista. Todavia, a normatização da vida pelo regramento do uso do espaço não se realiza sem conflitos. A população urbana, nos momentos da vida cotidiana, transgride-a constantemente como meio de sobrevivência a uma cidade produzida sob a égide capitalista, que possui como centro a acumulação do capital, em detrimento da reprodução da vida. É nesta perspectiva de desvendar as estratégias de normatização do uso e as transgressões diante o processo de dominação do espaço que a pesquisa se insere, tratando de compreender a produção de um lugar na metrópole paulistana, que se apresenta contraditoriamente como um espaço de normatização e transgressão na medida em que se constituiu como uma centralidade na periferia. Esta reflexão se construiu a partir do conhecimento dos sujeitos que produziram o espaço da Favela Monte Azul - zona sul do município de São Paulo - destacando as ações de uma organização não governamental chamada Associação Comunidade Monte Azul, por entender seu papel de destaque na produção da singularidade desta favela diante as demais da metrópole. Para tanto, analisamos as bases de sua matriz discursiva, as estratégias e ações e, principalmente, as articulações entre os sujeitos existentes na favela por meio do processo de "urbanização da favela" e das atividades culturais - teatro. A hipótese orientadora da pesquisa fundamentase, portanto, na idéia de uma urbanização que aprofunda a degradação da vida, produzindo tensões e conflitos ainda mais violentos que podem impedir a reprodução das relações de produção, levantando "barreiras" ao processo de acumulação. Para não interromper o ciclo, uma das estratégias utilizadas é a dominação do espaço pela territorialização de instituições na periferia, que levam a cabo as normas elaboradas pela ordem distante (Estado/ empresas privadas). Estas instituições, como as organizações não governamentais, tentam diluir as formas de organização e participação popular conforme introduzem a população às normas da cotidianeidade, isto é, às normatizações do uso através da legitimidade dada pela forma da propriedade e gestão dos serviços prestados. Contudo, essas mesmas instituições, na medida em que "absorvem" os conflitos, encontram-se em uma crise de sua própria reprodução.

\section{O processo de reestruturação da siderurgia mundial e brasileira: o caso da Companhia Siderúrgica Nacional}

Antônio Toledo Poso

Orientador: Prof. Dr. Armen Mamigonian

Esta pesquisa analisa o processo de reestruturação do setor siderúrgico mundial e brasileiro após os anos da década de 1990, o mesmo está representado pela internacionalização das empresas do setor, com a formação de grupos multinacionais, via fusões e aquisições, sendo impulsionado pelo processo intenso de privatizações, além da nova divisão internacional do trabalho com o crescimento da produção de aço dos países subdesenvolvidos, principalmente os asiáticos. Nesse sentido, buscamos analisar o comportamento da 
siderurgia nacional e, especialmente o da Companhia Siderúrgica Nacional (CSN) nessa nova conjuntura mundial, assim como, as suas conseqüências para a sócio-espacial brasileira. Podendo-se observar dois cenários possíveis: A desnacionalização dos ativos internos do setor siderúrgico nacional ou a inserção ativa do país nesse processo mundial de reestruturação.

\section{Uso sustentável da biodiversidade na Amazônia Brasileira: experiências atuais e perspectivas das bioindústrias de cosméticos e fitoterápicos}

Laís Mourão Miguel

Orientador: Prof. Dr. Wanderley Messias da Costa

A crescente demanda por produtos naturais desenvolvidos em bases sustentáveis tem promovido novas oportunidades de negócios na Amazônia brasileira. Como parte dessa tendência, os avanços das pesquisas na biotecnologia têm demonstrado papel fundamental na expansão desse potencial, impulsionando desse modo as cadeias produtivas das bioindústrias na região. Setores que merecem destaque na produção de bioprodutos em novas bases técnicas são representados pelas indústrias de cosméticos e fitoterápicos. Tendo como foco essas relações entre a biodiversidade, a biotecnologia e a bioindústria, o presente trabalho avalia algumas experiências em curso nesses segmentos, que envolvem um complexo sistema de parcerias entre empresas, universidades, institutos de pesquisa, agências financeiras oficiais, comunidades organizadas e cooperativas de dentro e fora da Região. Constituiu objeto de levantamento empírico, algumas indústrias de diferentes portes, centros de pesquisa e pequenos empreendimentos emergentes apoiados por Programas de Incubação de Empresas de Base Tecnológica em Belém e Manaus.

\section{Fronteiras terrestres e marítimas do Brasil: um contorno dinâmico}

\author{
Laércio Furquim Junior
}

Orientadora: Profa. Dra. Maria Mônica Arroyo

As fronteiras não acabaram como foi preconizado apressadamente na década de 1990. Elas se constituem de processos histórica e geograficamente dinâmicos. Os tipos, características e significados de fronteiras e limites se transformam ao longo dos tempos e se manifestam de diferentes formas em cada lugar e período onde ocorrem. Para além das características geográficas básicas, as fronteiras marítimas e terrestres do território brasileiro foram constituídas por diversos e distintos processos. As disputas territoriais seculares, que perpassaram períodos históricos desde os tempos coloniais, culminaram no processo de estabelecimento de fato das fronteiras terrestres brasileiras apenas no século XX. Hoje, já consolidadas, suas novas significações descartam sua função original ligada à expansão territorial, mas mantém uma outra, a de defesa, mesmo que sob novas formas de atuação. Atualmente, se verificam em diversos pontos dessas fronteiras, variados processos de ocupação, de interação internacional e de integração local, regional e nacional. Nas fronteiras marítimas do Brasil, percebe-se simultaneamente a dinâmica expansiva e a ocupação por exploração e por defesa. A origem desse processo se encontra no pós Segunda Guerra Mundial, quando os países costeiros dispararam, a partir de ação unilateral dos Estados Unidos, o processo de territorialização das águas marítimas que encerraram, ou ao menos limitaram a visão dos mares e oceanos inteiramente internacionalizados. Foram instituídas, no âmbito da ONU, faixas de soberania e de direitos de soberania aos países costeiros mar adentro. Seus processos de delimitação se tornaram foco geopolítico mediados por normatizações internacionais, cujas aplicações se encontram, ainda, em processo de estabelecimento. É o caso das 
Teses de Doutorado e Dissertações de Mestrado Defendidas

(Novembro de 2007 a Maio de 2007), pp. 193 - 205

fronteiras marítimas do Brasil que, em 2007, conseguiu referendar na ONU parte de suas requisições de expansão de suas águas jurisdicionais onde exerce direitos de soberania.

\section{O significado do trabalho na constituição da territorialidade dos assentados da Fazenda I panema, I peró-SP}

\section{Eduardo Castro}

Orientadora: Profa. Dra. Marta Inez Medeiros Marques

O objetivo deste trabalho é analisar como se realizam os processos de espacialização e de territorialização das famílias assentadas na Fazenda I panema, localizada no município de I peró-SP. Para alcançar tal objetivo, elegemos o trabalho como categoria central de nosso estudo. Trata-se de uma categoria fundamental na análise marxista e que está intimamente ligada com a vida, em sentido amplo, para as populações camponesas. A partir da descrição e análise das formas diversas de trabalho encontradas entre as famílias assentadas, realizadas seja no campo ou na cidade, avançamos no entendimento de como o espaço do lote e do assentamento é apropriado e construído pelos assentados, constituindo um território camponês em construção. A partir da luta pela terra e por manter-se nesta, trabalhando e vivendo com suas famílias, culminando no processo de territorialização, esse sujeito histórico, social e político se constitui como classe no contexto da formação social brasileira. Faz-se classe na medida em que se identifica com uma luta mais ampla, pela reforma agrária e por condições de vida e de trabalho dignas no meio rural. $O$ caso estudado se insere no contexto da discussão sobre a reforma agrária e do papel do campesinato na sociedade moderna, bem como de sua luta pelo reconhecimento do Estado, via políticas públicas, da sua importância em nossa sociedade.

\section{A ponte sobre o rio Oiapoque: uma ponte 'transoceânica' entre o Brasil e a França; o Mercosul e a União Européia?}

\author{
Maria Irene de Conte
}

Orientador: Prof. Dr. André Roberto Martin

Esta pesquisa analisa o papel geopolítico de uma ponte, em fase de projeto, que se localiza na fronteira entre dois países: Brasil e França (Guiana Francesa). O projeto de construção foi assinado pelos respectivos presidentes, em julho de 2005, durante as comemorações do ano do Brasil na França. Será construída sobre o rio Oiapoque, entre a cidade de mesmo nome e Saint-Georges, respectivamente nos territórios do Amapá e Guiana Francesa. Esta, sendo um dos territórios Ultramarinos franceses, é o único localizado na América do Sul. Esta proximidade faz do Brasil a maior fronteira terrestre com a França, significando uma importante parceria entre os dois países. Os interesses franceses na América do Sul, também pela localização estratégica de Kourou (Centro de lançamento de satélites franceses na Guiana), se fortalecem com a construção da ponte. Esta, juntamente à BR 156 (em fase final de asfaltamento), deverá possibilitar uma maior fluidez no veio de movimentação de mercadorias e de pessoas entre o porto de Santana (Amapá) e a Guiana Francesa. Afora a percepção econômica, problemas sociais se agravam, de forma insustentável, para as duas nações. Com a crescente mobilização entre os dois territórios motivada pela corrida pela extração de ouro, trabalho pago em Euro, aumenta a transmissão de doenças sexualmente transmissíveis (as DSTs) devido à prostituição e o descontrole do tráfico de drogas e de mulheres, principalmente de meninas. Este trabalho procura analisar em que esta ponte poderá colaborar para o desenvolvimento sócio-econômico regional, na solução de seus problemas sociais. Por último, se esta ponte poderá atuar como ponte entre os blocos econômicos no panorama da globalização: MERCOSUL e UNIÃO EUROPÉIA. 


\section{I mpactos da mineração de areia em planícies fluviais meândricas da bacia hidrográfica do Alto Tietê: o caso do rio Embu Guaçu, São Paulo - SP}

\section{João Cláudio Estaiano}

\section{Orientadora: Profa. Dra. Cleide Rodrigues}

Este estudo apresenta conhecimento geomorfológico sobre sistemas físicos meândricos e, em especial, busca o entendimento das atividades antrópicas sobre estes sistemas físicos, exemplificando assim um dos princípios fundamentais da Antropogeomorfologia ou Geomorfologia Antropogênica. A pesquisa tem como objetivo a análise qualitativa e quantitativa das mudanças produzidas pelas atividades de mineração de areia em um compartimento fluvial da planície meândrica do Rio Embu-Guaçu, setor sul do município de São Paulo (SP). O estudo das mudanças foi realizado com utilização da cartografia geomorfológica evolutiva como recurso analítico das condições do sistema físico em situação préintervenção e após 22 anos de extração de areia (situação durante intervenção). Para tanto, foram produzidos dois mapas geomorfológicos de detalhe da área de estudo: um, referente ao ano de 1981, e representa a morfologia original, o outro, referente à 2003, representa a morfologia antropogênica. A seleção e representação das formas, materiais e processos que constituem os mapas geomorfológicos, bem como sua análise comparativa baseiam-se em um conjunto de geoindicadores considerados como parâmetros para interpretação qualitativa e quantitativa.

\section{Efeitos da ação de cupins sobre propriedades de um perfil de solo em uma vertente da Represa Billings - São Bernardo do Campo/ SP}

\section{Gustavo Mattos Martins}

Orientador: Prof. Dr. Andreas Attila de Wolinsk Miklos
Considerando a importância de cupins como agentes da formação e funcionamento do solo, foram estudados a morfologia, granulometria e alguns parâmetros químicos do solo de um ninho de cupins do gênero Conitermes e de suas adjacências, para identificar e discutir as ações destes animais sobre as suas características e propriedades, principalmente acões sobre a morfologia e a química do perfil. O estudo foi feito por meio de perfis de solo que passaram pelo monte externo de um cupinzeiro e adjacências. Nos perfis foram identificados e descritos os horizontes e suas transições, as propriedades do solo e as organizações (feições de origem biológica) ali existentes, como: canais, câmaras e microagregados A descrição morfológica contemplou os aspectos de cor, textura, macroestrutura e consistência do solo. A descrição química incluiu as determinações do pH, matéria orgânica, alumínio e cátions trocáveis (cálcio, magnésio, potássio e sódio). E a análise granulométrica contemplou as frações argila, silte e areia. Os resultados obtidos mostraram diferenças químicas apreciáveis entre o solo do monte do ninho e solo do entorno, principalmente para os seguintes atributos: conteúdo de matéria orgânica, concentração de alumínio e concentração de cátios trocáveis, principalemente o magnésio e o potássio. Foram encontradas uma série de feições, principalmente câmaras e canais verticais preenchidos, que demonstraram o trabalho realizado pelos cupins no perfil decorrentes dos hábitos construtores. Tais feições comprovaram que os cupins têm importante papel na pedoplasmação da alterita da rocha e na formação de domínios microagregados.

\section{Comunidades de pescadores artesanais de Meleiras e Barreiras, Conceição da Barra - ES: I nserção dos territórios tradicionais na dinâmica econômica capixaba}

$$
\text { Margareth Maria Sales }
$$

Orientador: Prof. Dr. Antônio Carlos Robert Moraes 
Teses de Doutorado e Dissertações de Mestrado Defendidas

(Novembro de 2007 a Maio de 2007), pp. 193 - 205

A temática desta pesquisa busca entender como - espaço é construído e reconstruído socialmente por processos históricos constitutivos da dinâmica sociedade/natureza. Para este fim, utilizo como ponto de partida a realidade vivida pelas comunidades de pescadores artesanais de Meleiras e Barreiras estabelecidas no estuário do rio São Mateus, litoral norte do Espírito Santo, (Região Sudeste do Brasil) que tiveram seus territórios tradicionais inseridos na dinâmica econômica e nas políticas de conservação da região norte capixaba. Esta dinâmica, além de promover a valorização e a escassez das terras à beira-mar causa impactos sócioambientais que têm alterado tanto a reprodução dos recursos naturais estuarinos utilizados pelos pescadores artesanais, bem como a sua forma tradicional de uso. Além das comunidades pesqueiras, os principais agentes de transformação sócioespacial de Meleiras e Barreiras são, atualmente, a especulação imobiliária, o turismo, a fruticultura e o Estado. Este último por meio das políticas territoriais, em particular as políticas ambientais, com a implantação da APA de Conceição da Barra. 
